Mini review

\title{
Electrochemical, Electrochemiluminescent and Photoelectrochemical Immunosensors for Procalcitonin Detection: A review
}

\author{
Ming La \\ College of Chemistry and Chemical Engineering, Pingdingshan University, Pingdingshan, Henan \\ 467000, People's Republic of China \\ E-mail: mingla2011@163.com
}

doi: $10.20964 / 2020.07 .47$

Received: 6 March 2020 / Accepted: 28 April 2020 / Published: 10 June 2020

Procalcitonin (PCT) is a promising biomarker for identification of the origin and severity of sepsis, which is a deadly body infection. With the aim of early diagnostics of PCT, various PCT analytical technologies have been designed and applied all over the world. Electrochemistry-based immunosensors have attracted wide attention due to their low-cost, simplicity, sensitivity and simultaneous sensing performance, which can transduce the immunoreaction into detectable signal on functionalized solid surface. This review summarizes the development of electrochemistry-based immunosensors for PCT. More importantly, we also highlight nanomaterials-based signal amplification strategies that can remarkably improve the sensitivity of immunosensors. This work will be beneficial for the development of novel electrochemistry-based immunosensors for the detection of PCT and other important biomarkers.

Keywords: procalcitonin; electrochemistry; electrochemiluminescence; photoelectrochemistry; signal amplification

\section{FULL TEXT}

(C) 2020 The Authors. Published by ESG (www.electrochemsci.org). This article is an open access article distributed under the terms and conditions of the Creative Commons Attribution license (http://creativecommons.org/licenses/by/4.0/). 